\title{
Growth hormone therapy in a boy with X-linked spondyloepiphyseal dysplasia tarda: a 3-year observation
}

\author{
Yang $\mathrm{Li}^{1,2}$, Huahong $\mathrm{Wu}^{1}$, Hui $\mathrm{Li}^{1,2}$ \\ ${ }^{1}$ Department of Growth and Development, Capital Institute of Paediatrics, Beijing, China \\ ${ }^{2}$ Graduate School of Peking Union Medical College, Beijing, China
}

Key words: X-linked spondyloepiphyseal dysplasia tarda; TRAPPC2 gene; growth deficiency; growth hormone

A 6-year-old boy was first investigated in our clinic for a decrease of height velocity from age 3 years; the GV was about $4.3 \mathrm{~cm} /$ year. He was the firstborn by vaginal delivery at term, after an uneventful pregnancy. Birth weight was $3400 \mathrm{~g}$, birth length was $50.0 \mathrm{~cm}$. The parents were not related and had a normal stature: $169.0 \mathrm{~cm}$ and 158.2 $\mathrm{cm}$, respectively, with no family history of similar disease. At admittance his height was $109.0 \mathrm{~cm}$ (1.91 SD) and his weight was $18.1 \mathrm{~kg}(-1.27 \mathrm{SD})$. There was no other special clinical phenotype. Laboratory tests did not show any abnormalities in thyroid hormone, cortisol, and adrenocorticotrophic hormone. Hormone analysis revealed that the IGF-1 level was $102 \mathrm{ng} / \mathrm{mL}$ - the normal range at this age is $52-197 \mathrm{ng} / \mathrm{mL}$. The growth hormone level reached normal values after exercise challenge test $(17.53 \mathrm{ng} / \mathrm{mL})$. BA was 5.4 years old; he was diagnosed as failure to thrive.

At follow-up at the age of 6 years and 10 months, his height was $112.3 \mathrm{~cm}(-2.16 \mathrm{SD})$ and weight was 19.4 $\mathrm{kg}(-1.38 \mathrm{SD})$; therefore, we changed the diagnosis to idiopathic short stature. BA was 5.6 years old. Because the patient's height displayed a trend of continuous decline, the parents requested height intervention. After imaging and ultrasonic examination, he started rhGH therapy at a dose of $0.15 \mathrm{IU} \cdot \mathrm{kg}^{-1} \cdot \mathrm{d}^{-1}$, following careful considerations of the risks and benefits, as well as a discussion with the child's parents about the Chiari malformation type I found in the brain MRI.

The check-up visits were held every 3 months. Through the first year of treatment, his GV was 7.6 $\mathrm{cm} /$ year, $6.5 \mathrm{~cm} /$ year in the second year, and $6.5 \mathrm{~cm} /$ year in the third year. The progress of the patient's body weight and height gain, BA, and IGF-1 before and during rhGH treatment are shown in Table 1 and Fig. 1. Because the therapeutic effect on the child was lower than expected (the HtSDS increased by 0.96 SD in 31 months after treatment), we suggested that the pa- tient undergo genetic testing to further clarify the cause of short stature. At this time, we learned that the parents had concealed the family genetic medical history and the patient's uncle (mother's brother) was short, with a height of $134.0 \mathrm{~cm}$. The patient was examined by whole-genome sequencing in another hospital, and the result indicated that there was a splicing site mutation of the TRAPPC2 gene: c.-19-2A > G. The anterior and lateral X-ray of the spine and pelvis showed the anterior edge of the vertebral body becoming pointed in the middle and lower thoracic, and lumbar (shown in Fig. 1). The pathogenicity of this site has been previously reported [1], combined with the clinical phenotype and family history of the children, confirmed as SEDT-XL.

SEDT-XL is caused by a single gene mutation that plays a key role in the targeting and fusion of endoplasmic reticulum to Golgi transport vesicles [2]. Affected males exhibit linear growth deficiency beginning at around 6 8 years old. In early childhood, skeletal dysplasia leads to growth deficiency, and in later childhood, the child develops a disproportionately short stature (upper- to lower-body segment ratio is usually about 0.8 ), along with barrel chest and scoliosis [3]. However, the patient had no other recognizable specific facial features or other local deformities. According to literature reports, the adult height of Chinese male patients was mostly less than $150 \mathrm{~cm}$, and only 1 affected male had an adult height of $159 \mathrm{~cm}$ [4].

GH treatment for children with skeletal dysplasia has been used to improve height outcomes. To date, only 2 patients have reported the use of GH treatment with childhood growth retardation. In 2003, Shaw MA, et al.[5] reported a patient (c.333_336delGAAT mutation in exon 6) from a Slovak family, who started GH treatment at 10 years, but his height did not improve. In a case review of a pedigree, Li Juan et al. [6] mentioned that a 9-year-old proband (c.267_271delAAGAC mutation in exon 5) had 
Table 1. Anthropometric parameters, bone age, and insulin-like growth factor 1 of patient before and during rhGH treatment

\begin{tabular}{|c|c|c|c|c|c|c|}
\hline Age [years and months] & Height $[\mathrm{cm}]$ & Height SD & Weight [kg] & Weight SD & $\begin{array}{c}\text { BA } \\
\text { [years] }\end{array}$ & $\begin{array}{c}\text { IGF-1 } \\
{[\mathrm{ng} / \mathrm{mL}]}\end{array}$ \\
\hline 3 years and 10 months & 97.8 & -1.33 & 14.7 & -0.93 & & \\
\hline 4 years and 9 months & 103.4 & -1.50 & 17.9 & -0.24 & & \\
\hline 6 years and 1 month & 109.0 & -1.91 & 18.1 & -1.27 & 5.4 years * & \\
\hline $\begin{array}{l}6 \text { years and } 10 \text { months } \\
\text { (start of rhGH treatment) }\end{array}$ & 112.3 & -2.16 & 19.4 & -1.38 & 5.6 years & 143 \\
\hline 7 years and 1 month & 114.7 & -2.00 & 21.0 & -1.04 & & \\
\hline 7 years and 4 months & 117.2 & -1.82 & 22.7 & -0.71 & 6.5 years & 289 \\
\hline 7 years and 8 months & 118.9 & -1.78 & 24.0 & -0.58 & & 666 \\
\hline 7 years and 11 months & 120.5 & -1.71 & 23.5 & -0.89 & & 217 \\
\hline 8 years and 2 months & 122.4 & -1.58 & 27.3 & -0.13 & 7.8 years & 387 \\
\hline 8 years and 6 months & 124.6 & -1.52 & 26.5 & -0.54 & & \\
\hline 8 years and 11 months & 127.0 & -1.41 & 29.5 & -0.15 & 8.6 years & 450 \\
\hline 9 years and 2 months & 128.8 & -1.27 & 31.5 & 0.09 & & \\
\hline 9 years and 5 months & 130.7 & -1.20 & 31.0 & -0.17 & & \\
\hline
\end{tabular}

*the result was in the medical records of the patient, but because it was the result of another hospital, we did not see the original X-ray film; SD — standard deviation score; BA — bone age; IGF-1 — insulin-like growth factor 1

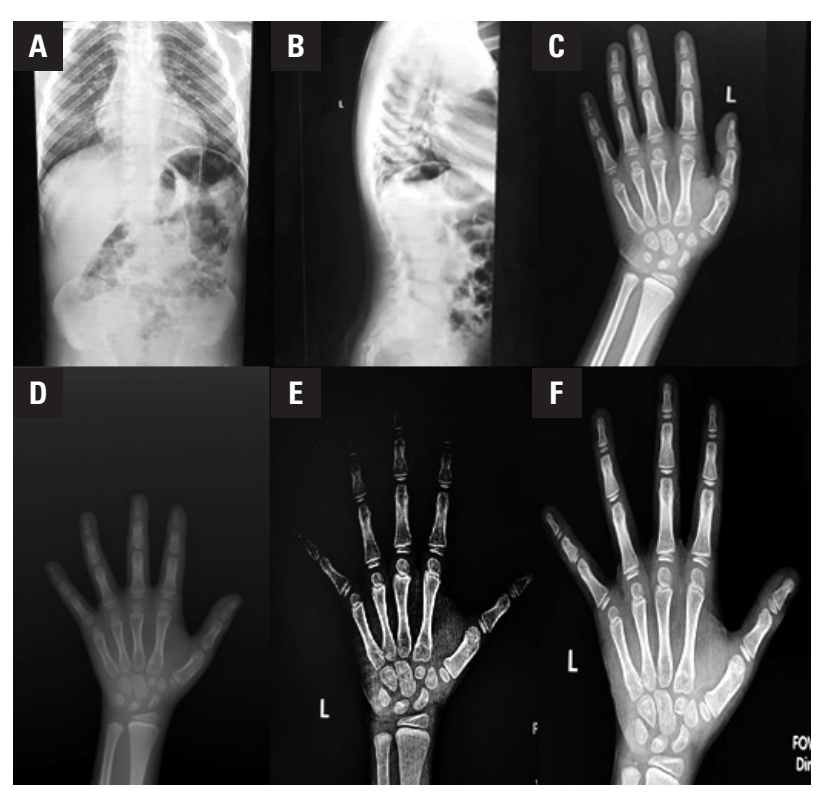

Figure 1. X-ray radiographs of the patient. A. Spine anteroposterior film. B. Anterior edge of the vertebral body becomes pointed in the middle and lower thoracic, and lumbar seen on the lateral view, and narrow intervertebral disc spaces. C. BA was 5.6 years at the age of 6 years and 10 months; D. BA was 6.5 years at the age of 7 years and 4 months; E. BA was 7.8 years at the age of 8 years and 2 months; F. BA was 8.6 years at the age of 8 years and 11 months

been treated with GH for 1 year, and his height increased by $5.1 \mathrm{~cm}$ during the treatment, which was close to the low limit of the normal growth rate of peers.

Herein, we report a case of an SEDT-XL patient who grew $18.4 \mathrm{~cm}$ after 31 months of GH treatment, reaching the $10^{\text {th }}$ percentile of the height of children of the same sex and age. So far, disproportionate and serious complications have not occurred. The parents intend to continue GH treatment under regular monitoring. We will follow the children for a long time to see if the improvement in height SDS sustains through adulthood.

\section{Authors' contributions}

All authors participated in the diagnostic pathways, wrote the manuscript, and revised the literature. All authors read and approved the final version of the manuscript.

\section{Funding}

The Special Fund of the Pediatric Medical Coordinated Development Center of Beijing Hospitals Authority, XTZD20180403.

\section{Conflict of interests}

All the authors declare no conflict of interest.

\section{References}

1. Szpiro-Tapia S, Sefiani A, Guilloud-Bataille M, et al. Spondyloepiphyseal dysplasia tarda: linkage with genetic markers from the distal short arm of the X chromosome. Hum Genet. 1988; 81(1): 61-63, doi: 10.1007/BF00283731, indexed in Pubmed: 3198127.

2. Sacher M, Jiang Y, Barrowman J, et al. TRAPP, a highly conserved novel complex on the cis-Golgi that mediates vesicle docking and fusion. EMBO J. 1998; 17(9): 2494-2503, doi: 10.1093/emboj/17.9.2494, indexed in Pubmed: 9564032.

3. Fiedler J, Le Merrer M, Mortier G, et al. X-linked spondyloepiphyseal dysplasia tarda: Novel and recurrent mutations in 13 European families. Hum Mutat. 2004; 24(1): 103, doi: 10.1002/humu.9254, indexed in Pubmed: 15221797.

4. Lin Y, Rao Sq, Yang Y, et al. [A novel mutation in the SEDL gene leading to $X$-linked spondyloepiphyseal dysplasia tarda in a large Chinese pedigree]. Zhonghua Yi Xue Yi Chuan Xue Za Zhi. 2008; 25(2): 150-153, doi: 10.3321/j.issn:1003-9406.2008.02.007, indexed in Pubmed: 18393234.

5. Shaw MA, Brunetti-Pierri N, Kádasi L, et al. Identification of three novel SEDL mutations, including mutation in the rare, non-canonical splice site of exon 4. Clin Genet. 2003; 64(3): 235-242, doi: 10.1034/j.1399-0004 .2003.00132.x, indexed in Pubmed: 12919139.

6. $\mathrm{Li} \mathrm{H}, \mathrm{Chai} \mathrm{Xj}$, Lu L, et al. [Analysis of SEDL gene mutation in a Chinese pedigree with $X$-linked spondyloepiphyseal dysplasia tarda]. Zhonghua Yi Xue Yi Chuan Xue Za Zhi . 2014; 31(5): 604-607, doi: 10.3760/cma.j.is sn.1003-9406.2014.05.014, indexed in Pubmed: 25297591. 